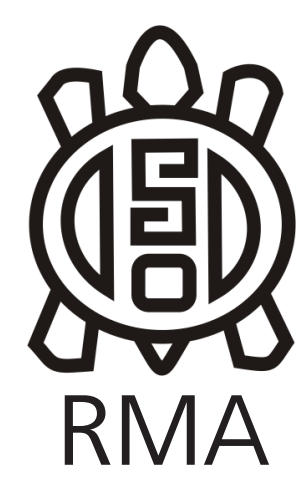

Museología

\title{
Reflexiones sobre las producciones discursivas presentes en el Museo Histórico "Fuerte Independencia"
}

\author{
Thoughts on the discourse formulations in the History Museum "Fuerte \\ Independencia" \\ Felicitas Sánchez Azcárate*
}

*Laboratorio de Arqueología Regional Bonaerense, Facultad de Humanidades, Universidad Nacional de Mar del Plata, Argentina. E-mail: feli21_sanchez@hotmail.com

\begin{abstract}
Resumen
Los museos históricos, entendidos en tanto dispositivos culturales, actúan como espacios que configuran y ofrecen determinados relatos sobre el pasado. Mediante la puesta en escena y su montaje, las exposiciones museográficas cristalizan estructuras de comprensión de la historia, el patrimonio y la memoria histórica. El artículo indaga los discursos sobre el devenir local ofrecidos en el Museo Histórico "Fuerte Independencia", ubicado en la ciudad de Tandil, en el centro-sur de la provincia de Buenos Aires. El análisis permite dilucidar cómo, por un lado, se elabora "Io indígena" en relación al universo de sentidos que buscan perfilar el pasado local y la identidad tandilense y, por otro, cómo se materializan en la propuesta museográfica los discursos sobre la alteridad de las sociedades indígenas. Así, simultáneamente a su producción como alteridad, "lo indígena" resulta congelado en un segmento concluido y/o acabado de la historia local.
\end{abstract}

Palabras clave: Museos históricos; Museografía; Construcciones discursivas; Alteridad; Sociedades indígenas.

\begin{abstract}
History museums, understood as cultural devices, acts as spaces that configure and offer certain stories about the past. By means of the staging, museographic displays unveil the way history, heritage and historic memory are understood. This paper reviews the discourses on the local history in History Museum "Fuerte Independencia," located in the city of Tandil, south-center of the Buenos Aires province. The analysis allows to elucidate, on the one hand, how the "indigenous" is constructed around the universe of senses that intend to outline the local past and the "Tandilian identity" and, on the other hand, how discourses on the alterity of indigenous communities are materialized in the museographic proposal. Thus, in displaying it as the alterity, "the indigenous" is confined into a concluded and finished-up segment of the local history.
\end{abstract}

Keywords: History museums; Museography; Discourse formulations; Alterity; Indigenous communities.

El siguiente trabajo busca analizar las construcciones discursivas sobre el pasado local diagnosticadas en el Museo Histórico "Fuerte Independencia", ubicado en la ciudad de Tandil, en el centro-sur de la provincia de Buenos Aires. Para tal fin, se indagará en el contexto de producción y reproducción de dichos discursos, priorizando el análisis del modo en que, a la par que se perfila el devenir local, se construye y define la alteridad de las poblaciones indígenas.

Se parte de asumir, como afirma Blasco, que los museos históricos resultan instituciones dedicadas a la recolección, conservación y exhibición pública de piezas, documentos y objetos materiales del pasado que proponen una perspectiva cronológica para ilustrar un determinado proceso histórico generalmente asociado a la construcción identitaria y que, de modos diversos "construyen un 'relato' del pasado que hace 'olvidar' determinadas imágenes y 'realzan' otras con una finalidad determinada" (Blasco 2007:1). De modo que se produce un "mecanismo de selección" que se efectúa dentro del museo, y que permite comprenderlos y abordarlos como espacios que intervienen activamente en la configuración de relatos y representaciones sociales sobre el pasado.

Entendidos como dispositivos culturales ${ }^{1}$, los espacios museográficos cristalizan determinadas maneras de

\footnotetext{
1 Se parte del concepto de cultura que propone Raymond Williams (1980 y 2000), dónde se involucra tanto la producción material como simbólica y/o intangible, en este caso, dentro de un tipo particular de institución: el museo.
} 
comprender la historia, el patrimonio y la memoria histórica. Los museos históricos, particularmente, juegan un rol clave como medio educativo-reflexivo en el nexo entre el pasado histórico y las sociedades actuales (Pereyra 2006) y actúan como lugares de memoria (Nora 2008). Esta memoria que reproduce y perpetúa el museo desempeña una función social, política y cultural de relevancia, no sólo por lo que representa el recuerdo, sino por el hecho de otorgar a éste estabilidad y materialidad.

\section{Como sostiene Fernández Bravo:}

"el museo opera bajo una forma
de funcionamiento que puede
compararse con la literatura,
el cine, la historia literaria o el
ensayo de interpretación, ya que
selecciona, ordena, clasifica y
muestra. Pero también oculta,
narra y compone" (2016:7).

En efecto, se pueden identificar en él diferentes modalidades de elaboración, reelaboración, presentación y reproducción de discursos (Verón 1993).

A partir del análisis de las exposiciones museográficas, es decir, el montaje de las salas y los métodos expositivos; y del guión museológico, entendido como la propuesta discursiva y comunicacional, se pretende develar aquellos discursos sobre el pasado local y regional ofrecidos y promovidos por el Museo Histórico "Fuerte Independencia"2.

Asimismo, debe precisarse que en la mayoría de los casos estos discursos no son elaborados a partir de la intencionalidad manifiesta de una persona o de un grupo de personas, por el contrario, devienen de causas, derroteros y situaciones diversas, y están atravesados por tensiones y contradicciones. Sin embargo, esto no implica que sean neutrales ni que dejen de configurar un determinado sistema de ideas y prácticas susceptibles de ser comprendido como un discurso articulado y articulador (Verón 1993).

En este sentido, durante los años 2014 y 2015 se realizaron visitas al museo y observaciones sistemáticas centradas principalmente en las exposiciones museográficas y su montaje $\mathrm{e}^{3}$. Esta información se complementó con el análisis de archivos institucionales presentes en la

\footnotetext{
${ }^{2}$ Es necesario destacar que este trabajo no analiza las recepciones de dichos discursos, un abordaje de ese tipo excede los límites de este artículo. Para una aproximación a este tipo de investigación ver: Reca, María Marta (2011). Estudio de público de museos: el aporte teóricometodológico de la semiótica. Revista do Museu de Arqueología e Etnología, 21: 357-369.

${ }^{3}$ Debe mencionarse que en la actualidad la institución ha modificado la propuesta museológica. Si bien la disposición de las salas y el recorrido por el museo continúa igual, existen actividades y propuestas nuevas que parecen tener como principal objetivo acercar el museo a la comunidad, así como abordar problemática actuales.
}

biblioteca/archivo del museo: estatutos, cuadernillos de circulación interna, folletería y fotografías. El abordaje de estos registros documentales producidos y utilizados como instrumentos institucionales fue fundamental para seleccionar información relativa a fechas importantes, personas involucradas en las etapas fundacionales, eventos realizados, vínculos institucionales activados e información sobre la procedencia de las colecciones arqueológicas. Por último, se investigó en los archivos de periódicos nacionales y locales. Se indagó en los archivos digitales de los periódicos de tirada nacional como "La Nación" y "Página 12". Para el abordaje de periódicos locales, se analizaron los archivos digitales de los diarios: "La voz de Tandil", "El Eco de Tandil" y "El Diario de Tandil". La triangulación de fuentes y datos permitió comprender el contexto situacional de los discursos aquí analizados.

\section{Contexto fundacional y de producción de discursos sobre el pasado}

De acuerdo a sus propios registros y textos de promoción/ divulgación, el museo comenzó a gestarse hacia fines de agosto de 1955, cuando se creó en la ciudad de Tandil la Institución tradicionalista "Fuerte Independencia". Según consta en su estatuto, se trató de una iniciativa impulsada por vecinos de la ciudad, aficionados al folklore y a las tradiciones criollas 4 . En palabras de sus fundadores el nombre Fuerte Independencia fue elegido "en homenaje a aquella avanzada heroica en la lucha de fronteras que asi llamará su jefe, y a la vez fundador de nuestra ciudad, el Brigadier General Don Martin Rodríguez"5. Estas expresiones en momentos fundacionales permitirán comprender los contextos de enunciación de los relatos sobre la historia local que reproducirá el museo, así como el lugar asignado a las poblaciones indígenas.

En sintonía con el espíritu tradicionalista, durante los primeros años la institución se centró en la enseñanza de las danzas folklóricas, buscaban "volcar en cada una de las manifestaciones, para recordación y conocimiento del pueblo, el más firme y puro deseo de cultivar, profundizando, a la vez, en la forma más veraz todas las cosas de nuestro acervo tradicional"6. En esta etapa, integrantes de la comisión directiva realizaron distintos viajes a la República Oriental del Uruguay entre los años 1957, 1958, 1960 y 1961, invitados por la Institución Tradicionalistas uruguaya "El Pericón". En 1958 durante uno de estos viajes, participaron del Primer Congreso Tradicionalista del Río de la Plata, el cual se realizó en el Ateneo de la ciudad de Montevideo y concurrieron delegaciones de países como Argentina, Uruguay y Brasil. El objetivo central fue establecer pautas comunes para orientar y estructurar al conjunto de instituciones

\footnotetext{
${ }^{4}$ Estatuto de la Asociación, 1964, p. 1.

${ }^{5}$ Cuadernillo informativo de la Inauguración y actividades del Museo y Biblioteca "Fuerte Independencia", Septiembre de 1963, p. 1.

${ }^{6}$ Ibidem
} 
tradicionalistas de la región?

La enseñanza de las danzas criollas para niños y adultos, la realización de fogones periódicos, conferencias, festivales musicales y de poesías criollas, exhibiciones de destreza gaucha y exposiciones de artes plásticas, fueron otorgándole a la Institución cada vez mayor visibilidad dentro del ámbito cultural y social de la ciudad.

Algunos años después, en junio de 1960, surgió desde la comisión directiva una sub-comisión compuesta por Emilse Giannibelli, Carlos Allende y Domingo Polpadre que impulsó la creación de una biblioteca folklórica tradicionalista. En este marco, se planteó la necesidad de adquirir un espacio propio para instalar la biblioteca y desarrollar el resto de las actividades, hecho que se concretó en el año 1962 mediante la compra del inmueble a Alfredo A. Cordonier. Ya instalados en la calle 4 de abril al 845, surgió la idea de fundar un museo en dicha propiedad. Así un año después, el 7 de septiembre de 1963, se inauguró el Museo Tradicionalista "Fuerte Independencia". Apadrinado por figuras destacadas del ámbito local como Antonio Santamarina y Rosa de Lalloz, y bendecido por el Monseñor Luis Actis, se creó el primer y único museo que, hasta la actualidad, transmite y divulga el pasado de la ciudad.

El surgimiento y desarrollo del museo, por aquel entonces denominado "Museo Tradicionalista Fuerte Independencia"s, se debió en gran medida a las donaciones realizadas por vecinos de la ciudad y a la entrega en "custodia" de otros tantos objetos, generando que a un año de su creación la institución contara con más de 600 piezas de valor histórico ${ }^{9}$. Resulta llamativo que dentro de las colecciones que el museo fue incorporando para representar el pasado local se encontraran una serie de objetos pertenecientes a los pueblos indígenas, muchos de los cuales fueron entregados por coleccionistas aficionados de la ciudad, pero también adquiridos a través de la compra-venta. En este último caso, se destaca una colección de lanzas y flechas que, según pudo constatarse, fue la única colección que el museo adquirió mediante una transacción comercial.

Lo dicho anteriormente permite sugerir cierta intencionalidad de reunir objetos "de indios", es decir, incorporar objetos valorados como indígenas en un museo cuya finalidad era representar el pasado tandilense. A partir de esto cabe preguntarse, ¿cuál fue el interés de los fundadores por exponer objetos pertenecientes a los pueblos indígenas? ¿Se pretendía incorporar la historia de estos pueblos en el relato sobre el pasado local?

${ }^{8}$ Con el transcurso del tiempo y a partir de la cantidad de donaciones que recibían, incluidos los documentos históricos que conforman el archivo de la institución, las autoridades del museo consideraron propicio modificar el nombre para definirlo como museo histórico.

${ }^{9}$ Cuadernillo informativo de la Inauguración y actividades del Museo y Biblioteca "Fuerte Independencia", Septiembre de 1963, p. 2.
}

Una posible respuesta a dichos interrogantes, teniendo en cuenta el perfil tradicionalista de la institución, es que las colecciones "de indios" fueron y son valoradas porque configuran una alteridad constitutiva que se vuelve funcional y necesaria para la composición de la autoimagen de la propia comunidad tandilense, reforzando de esta forma el "nosotros" frente al "ellos" o la "otredad" (Fernández Bravo 2016).

En este punto, es preciso describir las diferentes temporalidades en la conformación de las salas de exhibiciones, para así continuar dilucidando el contexto de producción de los discursos sobre el pasado local que el museo ofrece. Durante los primeros años la institución estuvo conformada por cuatro salas en las que se exhibían diversos objetos como la bandera Argentina correspondiente al Batallón 1 ero de Guardias Nacionales, marcas de hacienda, frenos y armas utilizadas por el ejército durante la "Campaña del Desierto", piezas de carretas y cañones pertenecientes a lo que había sido el Fuerte Independencia. También existía la reconstrucción de una pequeña Pulpería que incluía distintos objetos propios del periodo colonial. En la sala 1 se representaba la historia del alambrado, aunque también se exponían objetos de la vida cotidiana como faroles a kerosene y ollas. Cabe destacar la presencia de un carruaje del año 1827 perteneciente a Rómulo Pereyra Iraola, donado a la institución por Antonio Santamarina, quien fuera intendente de la ciudad y coleccionista autodidacta.

Con respecto al origen de las colecciones que iban conformando el acervo cultural del museo, se puede afirmar que fueron pocos los donantes que entregaron grandes colecciones y que éstas se efectuaron en distintos momentos. Entre quienes realizaron donaciones para conformar el Museo, se destacan las familias Santamarina, Allende, Figueroa y Olivero, cuyos aportes fueron centrales. Cada uno de los personajes "destacados" de dichas familias cuenta con una sala que lleva su nombre. El siguiente cuadro ilustra las características principales de dichos personajes y sus colecciones:

Por su parte, una gran cantidad de vecinos donaron de forma aislada diversos objetos, fotografías, obras de arte, etc. Entre ellos se destacan figuras como María Roca de De Marchi - hija de J. A. Roca- y Aldo Marcos de Castro Paz -sobrino bisnieto Roca-.

Otro actor relevante en el proceso de conformación del museo fueron las Fuerzas Armadas: uniformes, medallas, armas de fuego, cañones, tanques, aviones y minas constituyen una parte importante de las colecciones y llegaron a la institución a través de donaciones realizadas por militares. Asimismo, es pertinente mencionar que en la ciudad de Tandil funciona desde mediados de la década de 1940 la VI Brigada Aérea, un importante destacamento militar dependiente de la Fuerza Aérea, situado en el aeropuerto de la ciudad. 


\begin{tabular}{|c|c|c|c|}
\hline Familia & $\begin{array}{l}\text { Personaje } \\
\text { destacado }\end{array}$ & Ocupación & Principales colecciones donadas \\
\hline Santamarina & $\begin{array}{c}\text { Antonio } \\
\text { Santamarina }\end{array}$ & $\begin{array}{l}\text { Hacendado y Político: } \\
\text { miembro del Concejo } \\
\text { Deliberante de la } \\
\text { Ciudad de Buenos Aires; } \\
\text { Diputado provincial y } \\
\text { nacional; Intendente de } \\
\text { Tandil (1914-1917); } \\
\text { Senador Nacional. } \\
\text { Presidente de la } \\
\text { Academia Nacional de } \\
\text { Bellas Artes. }\end{array}$ & $\begin{array}{l}\text { Coches de época, obras de arte, } \\
\text { mates, herraduras, estribos, } \\
\text { cuchillos, etc. }\end{array}$ \\
\hline Olivero & $\begin{array}{l}\text { Eduardo } \\
\text { Olivero }\end{array}$ & $\begin{array}{c}\text { Aviador: participó en la } \\
\text { Primera Guerra } \\
\text { Mundial. }\end{array}$ & $\begin{array}{l}\text { Libros, fotos, placas, banderas, } \\
\text { medallas, etc. }\end{array}$ \\
\hline Figueroa & $\begin{array}{c}\text { Juan Adolfo } \\
\text { Figueroa }\end{array}$ & $\begin{array}{c}\text { Hacendado y } \\
\text { Juez de Paz de Tandil: } \\
\text { desempeñó esta función } \\
\text { durante los primeros } \\
\text { años de la década de } \\
1870 .\end{array}$ & $\begin{array}{l}\text { Mates, herraduras, vestimenta } \\
\text { "criolla", espuelas, estribos, } \\
\text { cuchillos, etc. }\end{array}$ \\
\hline Allende & $\begin{array}{l}\text { Carlos } \\
\text { Allende }\end{array}$ & $\begin{array}{l}\text { Artista plástico: creó la } \\
\text { Fábrica La Movediza, } \\
\text { primera fábrica de } \\
\text { cuchillos de hierro } \\
\text { forjado del país. }\end{array}$ & $\begin{array}{c}\text { Cuchillos, armas, bayonetas, } \\
\text { instrumentos musicales, mates, } \\
\text { espuelas, rastras, estribos, etc., } \\
\text { esculturas y obras de arte. }\end{array}$ \\
\hline
\end{tabular}

Tabla 1: Principales donantes del Museo Histórico "Fuerte Independencia". Elaboración propia.

Table 1: Main donors of the Historical Museum "Fuerte Independencia". Own creation.
En este sentido, se constató que Ricardo Ballent, quien desempeñó el rol de presidente durante más de 40 años, tuvo un papel preponderante dentro del museo al actuar como intermediario entre ambas instituciones. Su labor profesional y su fuerte identificación con la tradición militar posibilitaron la creación de vínculos con familias tradicionales de la ciudad, así como con las Fuerzas Armadas ${ }^{10}$.

A medida que el museo fue creciendo, la comisión directiva comenzó a plantearse la necesidad de realizar refacciones, ampliaciones y la posibilidad de comprar inmuebles linderos, para exponer la creciente cantidad de objetos que incrementaban el patrimonio de la institución. De esta forma, luego de comprar el inmueble original, se adquirió el galpón que actualmente alberga la sala 14: "Don Ricardo Ballent", los baños y la sala 15: "Imágenes Religiosas".

En un segundo momento se incorporó el galpón que

\footnotetext{
${ }^{10}$ Ricardo Ballent nació en la ciudad de Tandil el 8 de marzo de 1926, dedicó su vida a la carrera de martillero público donde adquirió gran prestigio y fue construyendo vínculos con las familias más destacadas de la ciudad, muchas de las cuales luego donarían piezas a la institución. Junto con Carlos Allende fue uno de los fundadores del museo, presidiendo la institución desde el año 1963 hasta su muerte, en el año 2005. Según personas allegadas a Ballent, se interesaba mucho por mantener lazos con las Fuerzas Armadas, nunca faltaba a los actos militares, festejaba las fechas patrias e invitaba a generales y tenientes al museo para rendirles homenaje.
}

alberga la Sala 9: "El Campo" y un inmueble situado sobre la Avenida Marconi ubicado en la misma manzana que el Museo, donde se encuentran hoy las salas 10 "Herrería", 11 "Malvinas", 12"Telégrafo/Ferrocarril" y 13 "Ciencias Naturales". Así la institución llegó a ocupar casi la totalidad de la manzana, cubriendo una superficie aproximada de más de 2000 m2.

Por su parte, las salas 12 y 13 fueron construidas a partir de la desaparición de dos museos que existían en la ciudad: el "Museo Ferroviario"11 que estaba ubicado en las calles Aristóbulo del Valle y Alem y existía desde el año 1994, y el "Museo de Ciencias Naturales" que desde el 2005 funcionaba en la calle Mitre al 386"2. Ambos debieron cerrar por cuestiones económicas y se trasladaron, en parte, al Museo Histórico entre los años 2011 y 2013. Dentro de la sala 13 existe un sector de geología que por cuestiones de espacio no está exhibido.

En el año 2000 se inauguró la sala de los carruajes -hoy "El Campo"- y se recibió la donación de las pertenencias del escultor y artista plástico Carlos Allende. Tiempo después, durante el 2007, se cambiaron los pisos y las instalaciones eléctricas de la "Sala Principal" y de "la Pulpería".

Durante el 2010 comenzó a remodelarse la sala “La

\footnotetext{
${ }^{11}$ Diario La Nación. "Un museo que rescata la magia del antiguo ferrocarril", 9 de julio de 2005

12 Ordenanza Municipal № 8060/2000. Creación del "Museo de Ciencias Naturales", Tandil, 2005.
} 


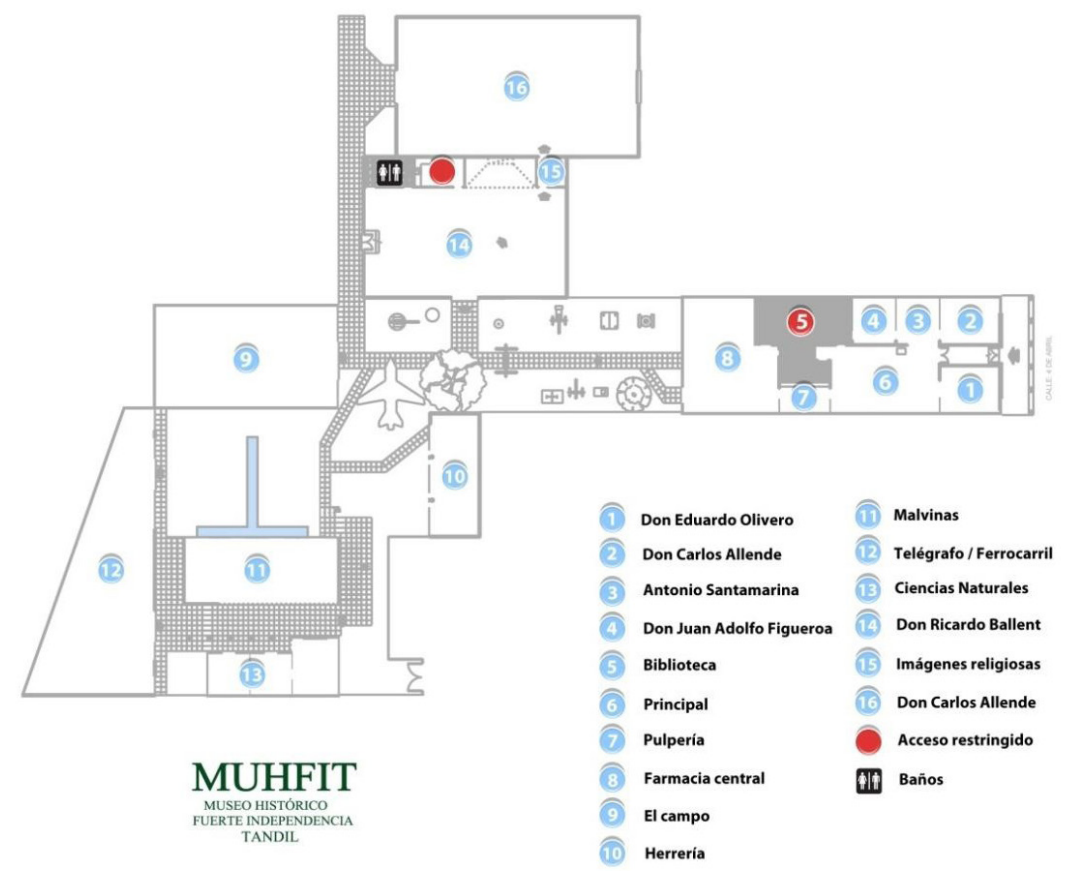

Figura 1: Plano actual del Museo Histórico Fuerte Independencia. Archivo de la institución.

Figure 1: Current blueprint of the History Museum Fuerte Independencia. Institution's file.
Farmacia" que se inauguró en julio del 2011 gracias a la donación de la familia Berlari, quienes en el año 2007 habían cedido todo el mobiliario: frascos, balanzas, botiquines y demás elementos de la histórica Farmacia Central de la ciudad, ubicada en Rodríguez al 400. La obra se financió, en parte, gracias a los recursos reunidos en un asado que el museo realizó por los festejos del Bicentenario en las instalaciones de la Sociedad Rural. ${ }^{13}$

El último evento importante relativo a las ampliaciones del museo fue la inauguración de la Sala "Islas Malvinas", que finalmente se concretó en mayo del 2014 luego de más de 3 años de trabajo y complicaciones financieras. ${ }^{14}$ La fecha elegida fue el 1 de mayo en conmemoración al bautismo de fuego de la fuerza aérea en la Guerra de Malvinas. Para los miembros de la comisión esta sala sería la más moderna e interactiva. ${ }^{15}$

Así quedó constituido el Museo conformado por un total de 15 salas expositivas, espacios al descubierto y una Biblioteca/Archivo que completa el recorrido (Figura 1).

En este conjunto de espacios y subdivisiones se exponen, tanto en vitrinas como en estantes, muebles antiguos e incluso sobre el piso, una gran cantidad y variedad de objetos. En efecto, todas las salas se encuentran colmadas de materiales en exhibición permanente. Se abre, entonces, el interrogante sobre la existencia de

\footnotetext{
${ }^{13}$ Diario El Eco de Tandil. "El Museo Fuerte Independencia inauguró nueva sala con reliquias de la Farmacia Central", 9 de Julio de 2011.

${ }^{14}$ Diario La Voz de Tandil. "Lanzan campaña para mejorar la Sala Islas Malvinas del Museo", 16 de diciembre del 2011, LOCALES.

${ }^{15}$ Diario El Eco de Tandil. "Se inauguró la muestra en la Sala Malvinas del Museo del Fuerte", 2 de mayo de 2014; Diario El Diario de Tandil. "Reinauguran la Isla Malvinas en el Museo Fuerte Independencia, 30 de abril del 2014, SOCIEDAD.
}

criterios selectivos para decidir qué se expone y qué no, ya que a simple vista pareciera no existir ninguno. Podríamos afirmar, a partir del análisis realizado, que es el supuesto vacio y/o la ausencia de tradiciones lo que moviliza la necesidad de incorporar continuamente objetos que, tras ingresar al museo, se transfiguran en parte del patrimonio de la ciudad ${ }^{16}$, montando una escenografía formada por cosas donde la comunidad se vea representada (Fernández Bravo 2016). En palabras de sus propios fundadores, es el "homenaje a aquella avanzada heroica en la lucha de fronteras" lo que da origen al nombre del museo y, al mismo tiempo, refuerza los discursos que allí se reproducen, colocando -como buscaremos elucidar en el siguiente apartado- al indígena como la alteridad del pasado-presente.

\section{Propuesta museográfica sobre "lo indígena"}

De todas las salas que componen la propuesta museográfica, "lo indígena" aparece confinado a un espacio concreto: la sala "Don Carlos Allende", un reconocido artista plástico y coleccionista de la ciudad que llegó a poseer una amplia y diversa colección de objetos que exponía en un museo particular que había montando en su propia casa. ${ }^{17}$ En la numeración propuesta por el museo es la sala 2, es pequeña y está compuesta por vitrinas de madera, cartelería asociada a los objetos, cuadros, láminas y fotografías expuestas en las paredes.

\footnotetext{
16 Es interesante este enfoque propuesto por Álvaro Fernández Bravo (2016) quien sostiene que la burguesía criolla latinoamericana, con el afán de construir una autoimagen distinta a la formada por las metrópolis europeas de las cuales se habían independizado, manipuló la cultura material indígena y/o popular, atribuyéndole un valor simbólico estratégico con el principal propósito de equiparar un patrimonio cultural percibido como vacio o deficitario.

17 Centro guía de turismo de Tandil: "Museo Histórico General de Curiosidades Obra de Don Carlos Allende". En: Piedra Libre, 1974.
} 


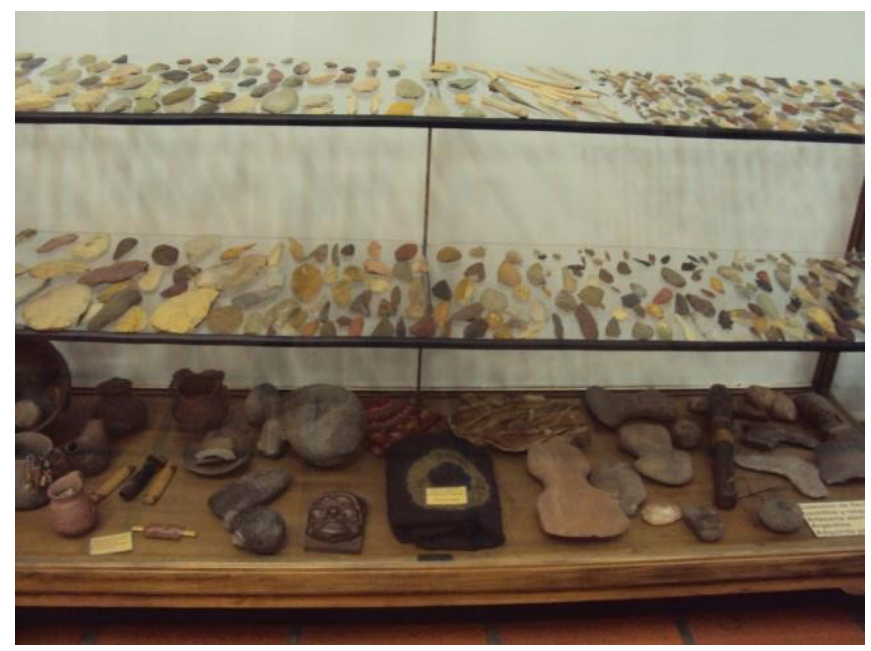

Figura 2: Material lítico diverso expuesto en vitrina. Fotografía propia.

Figure 2: Various lithic material on display. Own photography.

Se encuentra ubicada al comienza del recorrido (ver Figura 1).

Allí se visualizan diversos objetos como morteros, puntas de flechas, vasijas, lanzas y boleadoras. La mayoría de éstos se encuentran expuestos en vitrinas, estantes 0 colocados sobre el piso de la sala (Figura 2, y 3).

Estos objetos se combinan con seis fotografías de estos pueblos ya incorporados al Estado nacional, exhibidas en las paredes de la sala, colocadas frente a las vitrinas donde se exponen la materialidad de "lo indígena". Concretamente las fotos corresponden a la familia del cacique Manuel Namuncurá, definido en este caso como "el último soberano de los pampas". Ella produce la exaltación de su figura generando cierta proximidad (Figura 4).

Dicha colección de imágenes se completa con dos fotografías de festividades y/o rituales autóctonos en cuyo epígrafe puede leerse: "Grupo de loncoteadores preparados para iniciar los bailes sagrados" (Figura 5). Ninguna de las imágenes mencionadas especifica cuándo fue tomada, dónde ni por quién. Opera aquí la empresa de apropiación de cosas que emprenden los museos, en donde se produce el proceso mágico de impropiedad -la apropiación de algo ajeno- que luego se vuelve patrimonio de la comunidad, en algunos casos para reflejarse y proyectarse, en otros, para diferenciarse (Fernández Bravo 2016).

Por último, se exponen en la sala colecciones de cuchillos y esculturas alusivas a la figura del "gaucho", en su mayoría elaboradas por el artista Carlos Allende, quién da nombre a la sala. Aquí, los discursos propuestos sobre "Io indígena" dialogan con los discursos sobre "lo gaucho", pero un tipo específico de guacho que es representado y exhibido a partir de objetos que denotan agresividad como cuchillos, lanzas y boleadoras.

De esta forma, los objetos asignados a las poblaciones indígenas se entrelazan con fotografías del siglo XIX y principios del $X X$ y, también, con materiales alusivos a la figura del gaucho. La información escrita que acompaña los objetos hace referencia a las familias donantes y, en algunos casos, a la región donde fueron halladas. Se puede citar como ejemplo un cartel donde se lee: "46 puntas de flechas halladas en el cerro El Sombrerito (Partido de Benito Juárez). Donación: Daniel Caresia Lamas". El criterio adoptado permite identificar a los apropiadores de objetos. Se materializa aquí la operación de despojo anteriormente mencionada, pero en este caso los objetos no pasan a ser de toda la comunidad, sino que se presentan como "propiedad" de los coleccionistas, glorificando sus figuras como ciudadanos destacados e ilustres.

Dentro de esta sala también se visualiza una amplia lámina de aproximadamente 1 metro de alto por 2 de ancho, allí se describen ciertas características físicas de los grupos que habitaban la región pampeana. Puede leerse: "Eran corpulentos, fuertes, de piel oscura, cabellera abundante, lacia y renegrida, de ojos almendrados y facciones rudas". Dicha descripción dialoga con los sentidos discursivos hegemónicos sobre "lo indígena", reforzando la caracterización de indio "salvaje" y efectuando una asociación de los rasgos con atributos o cualidades (Vera et al. 2014).

La muestra ofrecida permite entrever una perspectiva que plantea la existencia de los grupos indígenas en una temporalidad artificialmente arcaica. Se hace evidente la referencia al indígena como la otredad, reforzando al mismo tiempo la noción propia de ciudadano tandilense que reproduce la muestra, asociado principalmente a la

Figura 3: Colección de lanzas y alfarería expuesta en vitrina. Fotografía propia.

Figure 3: Collection of spears and pottery on display. Own photography.

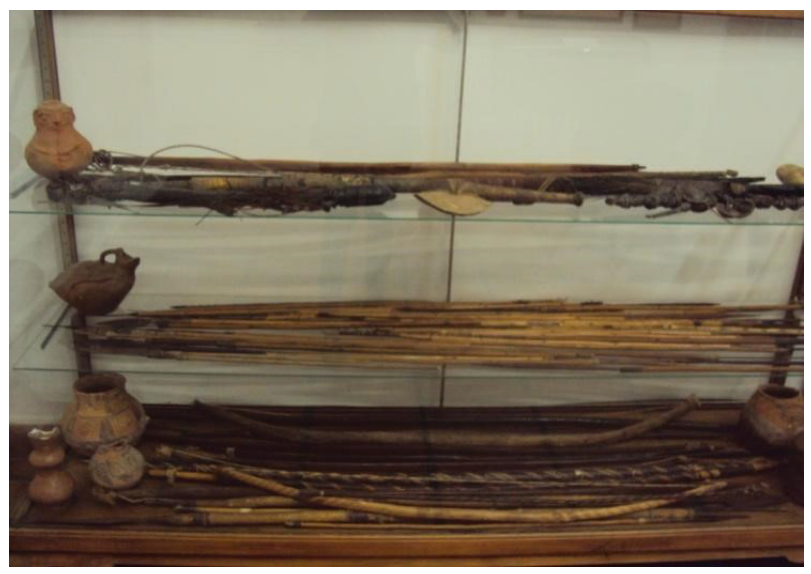




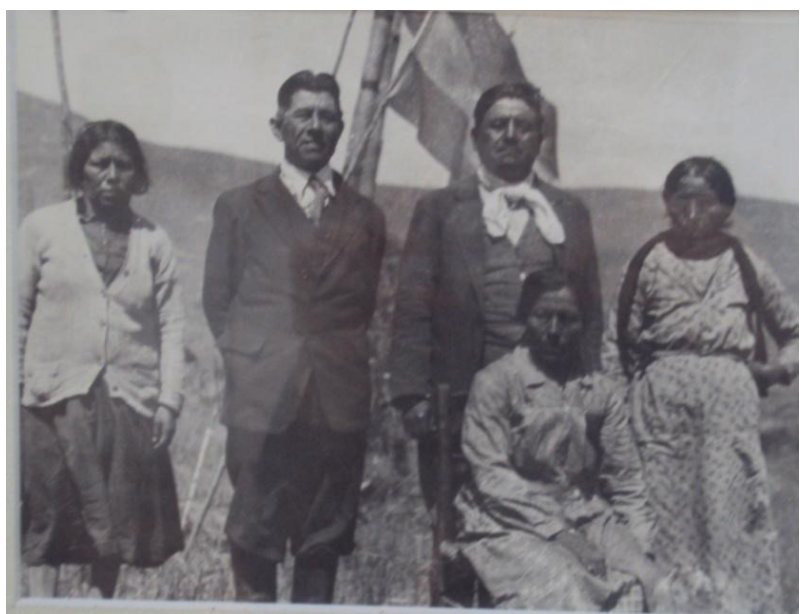

Figura 4: Fotografía de la familia de Manuel Namuncurá ubicada en la pared sur de la sala Allende. Archivo de la Institución.

Figure 4: Photography of Manuel Namuncurá's family, located in the South wall of Allende room. Institution's file.

tradición criolla y militar.

\section{Articulación de "lo indígena" en la propuesta museológica}

Como se mencionó previamente, las salas que conforman el museo son diversas y se encuentran colmadas de objetos exhibidos de forma permanente. Asimismo, cada sala parece conformar una totalidad en sí misma, un fragmento de la historia o un espacio cerrado sin orden aparente con el resto de las salas.

La sala indígena se encuentra en el comienzo del recorrido, está enfrentada a la sala 1: "Don Eduardo Olivero", pequeña habitación en la que se exponen pertenencias de dicho personaje que participó como aviador durante la Primera Guerra Mundial, y es continuada por la sala 3: "Antonio Santamarina", conformada por objetos diversos, cuadros -se destacan una pintura de cuerpo entero de Julio A. Roca y otra del Coronel José Benito Machado-, también se exponen armas de fuego, cañones pertenecientes al antiguo Fuerte, así como imágenes de militares que participaron de las avanzadas militares en la región. La sala siguiente es la 4: "Don Juan Adolfo Figueroa", en esta se exponen objetos de la colección de dicho personaje: mates, ponchos, herraduras, armas de fuego, cuchillos, etc. El resto de las salas que llevan el nombre de personajes destacados de la ciudad, exponen objetos de características similares. Continúa el recorrido con distintas reconstrucciones de época: Pulpería, Farmacia, Herrería y el Campo. Completan el recorrido otras salas temáticas como "Malvinas", "Ciencias Naturales" e "Imágenes Religiosas".

De esta forma, pueden identificarse algunas estrategias museográficas que se replican en la mayoría de las salas, resultando indicios de los discursos ofrecidos por el museo. A continuación quisiéramos repesar algunos núcleos temáticos que logramos identificar.

\section{* Militarización del pasado local}

La exaltación de "héroes" o "grandes hombres" particularmente del ámbito local, pero también nacional. En este sentido, se destacan personajes locales y familias de cierto prestigio -Olivera, Santamarina, Allende, Figueroa-, así como militares que actuaron en "la frontera contra el indio" -según puede leerse en la cartelería- como el coronel José Benito Machado. También se distinguen figuras de alcance nacional como Julio A. Roca. Por su parte, en la sala indígena se hace referencia a la figura de Manuel Namuncurá como el "último soberano de los pampas", se produce la exaltación de su figura, generando cierta proximidad con este cacique. Este reconocimiento a la particular figura de Namuncurá parece relacionarse con su labor como coronel del ejército argentino, así como con la idea del "buen salvaje", que una vez sometido colabora e incluso llega a adoptar los modos de vida del hispano-criollo. En este sentido, la figura del cacique representa dentro de la sala indígena el ejemplo y/o modelo a imitar.

Por otro lado, la celebración a las gestas militares, particularmente las relacionadas con el avance de la frontera y, ya avanzado el siglo XX, la Guerra de Malvinas. La alusión a dichos sucesos se relaciona con las características de los objetos expuestos: cañones, armas de fuego, uniformes militares, banderas, escudos, tanques, aviones, minas, entre otros. Estos objetos que se encuentran presentes en la mayor parte del recorrido, refuerzan, actualizan y consolidan el relato histórico dominante que ofrece el museo, que tiene como hecho fundacional la construcción del Fuerte y, implícitamente, la avanzada sobre las parcialidades indígenas. En este

Figura 5: Fotografía ubicada en la pared sur de la sala Allende cuyo epígrafe dice: "Ritual autóctono". Archivo de la Institución.

Figure 5: Photography located on the South wall of Allende room with a caption that reads: "Indigenous ritual." Institution's file.

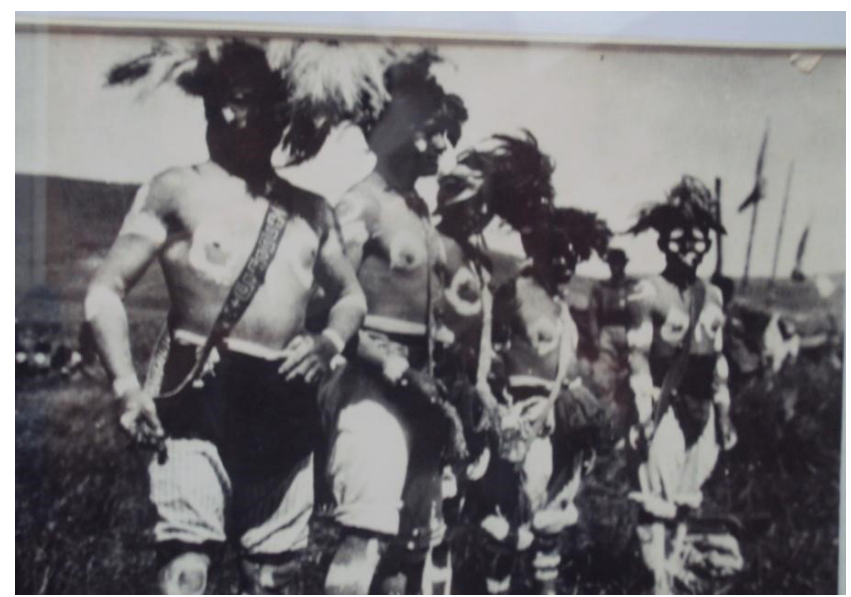


aspecto la figura de Ricardo Ballent cobra centralidad, su rol como presidente de la institución, sumado a su afición por las Fuerzas Armadas delimitaron en gran medida el perfil militarista del museo. En este sentido, se puede afirmar que existe una fuerte impronta de la enseñanza patriótica (Bertoni 2001) contenida dentro de la muestra.

\section{* El gaucho como modelo identitario}

El lugar relevante que adquiere la figura del gaucho como síntesis de la identidad regional es otro aspecto que se destaca en el recorrido. Objetos construidos o intencionalmente asignadas como pertenecientes a "lo gaucho" están presentes en la mayoría de las salas del museo, desde mates y cuchillos hasta obras de arte y esculturas referidas a la figura o significadas como del gaucho. En este caso se produce una estrategia discursiva interesante, el gaucho es exhibido en un primer momento un tanto distante, representado junto a "lo indígena" en la sala "Allende" a partir objetos que acentúan su agresividad. Sin embargo, continuando el recorrido este montaje se modifica y el guacho aparece asociado a objetos de la vida cotidiana, representativos del "criollismo": herraduras, espuelas, ponchos, etc. Es decir, su figura pasa de exhibirse paralelamente junto a la otredad -el indígena- a configurase como representante de lo "propio", como el símbolo de "lo nuestro". Se verifica aquí el carácter cambiante, provisorio y móvil de toda exposición, que al estar compuesta por objetos reunidos en una colección pueden cambiar de lugar con el fin de adaptarlos a una representación, relato y/o discurso funcional a la comunidad que busca representar (Fernández Bravo 2016).

Dichos criterios permiten una aproximación a los discursos que se configuran en la muestra museográfica, qué aspectos y personajes del pasado se priorizan en detrimento de otros, es decir, qué debe ser recordado, perpetuado y celebrado, y qué no. La memoria histórica que se reproduce dentro del museo y aquello que potencialmente se pretende ser, queda condicionada por los criterios adoptados a la hora de elaborar dicha exposición.

\section{Reflexiones finales}

Una primera aproximación al análisis de las exposiciones y del guión museográfico permite visibilizar una fuerte impronta de la enseñanza patriótica (Bertoni 2001) presente dentro de la muestra. En este sentido, este tipo de museos históricos, al igual que los textos de enseñanza, tienen como principal función retomar e interactuar con los discursos que colaboran con la conformación del "espíritu nacional". Así, el objeto museográfico queda atrapado por la imagen de la palabra escrita y convertido en fetiche de un modo de practicar la transmisión cívica (Morales Moreno 2009). Se pueden observar, en este sentido, coincidencias entre los discursos promovidos por el museo y la escuela, lo cual no resulta extraño si se tiene en cuenta que en sus etapas constitutivas ambas instituciones fueron pensadas e instituidas para fortalecer la "identidad nacional" (Lionetti 2007, Novaro 2003).

Por su parte, dentro de la sala "Don Carlos Allende" los objetos asignados a los pueblos indígenas y sus fotografías se combinan con objetos atribuidos a la figura del gaucho, configurando una única exposición. Particularmente en esta sala, el gaucho es representado a partir de cuchillos y lanzas, objetos que manifiestan cierta rudeza y agresividad. Así, dentro de esta sala "lo indígena" y "lo guacho" comparten características y modos expositivos. Sin embargo, avanzado el recorrido la figura del indio desaparece, mientras que el gaucho es exhibido en la mayoría de la salas, principalmente mediante objetos de la vida cotidiana y/o relativos a los trabajos rurales. Opera de esta forma un cambio en el modo de representar "lo guacho".

De esta forma, pueden trazarse similitudes con la producción discursiva sobre "lo gaucho" presente en el libro "Martin Fierro". En "La ida"-1872-, el gaucho es representado rebelde, vago y despreciable, mientras que en "La Vuelta"-1879- se produce una transformación y el personaje gauchesco aparece más reflexivo y moderado, en cierto sentido "domesticado". La operación Lugones (Pérez Calarco 2012, Sorensen Goodrich 1997) que dicho intelectual realizaría sobre esta obra literaria en el contexto del centenario de la Revolución de Mayo permitió que, en la actualidad, se perciba a este gaucho como un ícono de la argentinidad y de lo criollo, es decir, como símbolo de la identidad nacional.

Por otro parte, puede reconocerse la intención de incorporar en la muestra el pasado prehispánico y colonial, sobre todo si se tiene en cuenta que la ciudad de Tandil se fundó en el año 1823 a partir del "Fuerte Independencia", como poblado de frontera. Pero en este caso, la muestra no permite trazar líneas de continuidad entre ese pasado y el que se abre a partir de la fundación de la ciudad, por el contrario, lo indígena aparece como atemporal y ajeno.

Cabe preguntarse, entonces, ¿por qué razón se exponen estos objetos? Una primera respuesta puede relacionarse con el propósito de equipar un patrimonio cultural percibido como vacio o deficitario, en este caso representativo de la "otredad", de lo ajeno y externo a la propia comunidad, lo que permite reforzar y/o fortalecer la autopercepción identitaria que propugna el museo. En este sentido, la muestra museográfica incorpora criterios expositivos y "modos de contar" que posibilitan identificar un relato sobre el pasado donde se recuerdan y perpetúan determinados hechos y actores sociales, y se invisibilizan otros. A su vez, se proyecta un ideal de comunidad, una subjetividad futura donde se edifican determinados prototipos de "ciudadanos". 
Ciertos personajes del ámbito local son enaltecidos, representados como "ciudadanos ilustres", "pioneros fundadores", "hacendados exitosos" y "militares destacados"; el mismo mecanismo opera sobre la figura del gaucho. Este último aspecto se vincula con el origen tradicionalista del museo, siendo el gaucho el sujeto social que adquiere mayor jerarquía y visibilidad a la hora de abordar el pasado regional. A través de esto se expresa la objetivación de un discurso cultural / ideológico concreto: el "discurso criollista" (Prieto 1988). Este discurso surge entre fines del siglo XIX y comienzos del $X X$, en pleno contexto de conformación del Estado Nacional. Las fuertes oleadas inmigratorias de aquel periodo y el afán del Estado decimonónico por crear una nación culturalmente homogénea, generó en el sector gubernamental la necesidad de construir símbolos que identificaran y representaran al Estado nacional. De esta forma, percibido como emblema de la argentinidad, la figura del gaucho se transformó en objeto de culto capaz de contener los rasgos esenciales de la nacionalidad argentina (Cattaruzza, 2001).

Este gaucho enaltecido en la muestra y presente en la mayoría de las salas, se percibe como capaz de sintetizar los rasgos de la "nacionalidad argentina", de la "patria". Los pueblos indígenas, mientras tanto, son expuestos por fuera de aquella configuración identitaria y representados a partir de tres características generales: "homogeneidad", "salvajismo" y "estatismo". Así, se coloca al indígena como un actor social en extinción, una pieza propia del museo que reafirma y ayuda a configurar la propia identidad de la comunidad. De esta forma, el punto de partida de la construcción identitaria que difunde el museo es el hombre blanco civilizado y civilizador.

Lo anteriormente expresado permite comprender que la perspectiva discursiva predominante de toda la muestra es una reactualización constante de aquel relato fundacional, basado en el "...homenaje a aquella avanzada heroica en la lucha de fronteras...". Por esta razón, aunque los "indios" no se mencionen explícitamente en la mayor parte de la muestra y su presencia esté confinada a una pequeña sala, son la fantasmal alteridad siempre presente, es decir, el interlocutor necesario para que esa heroica lucha se reproduzca y se actualice constantemente. Así, los discursos que ofrece el museo adquieren sentido en el presente y se proyectan delimitando una subjetividad futura.

Mar del Plata, 18 de marzo de 2020

\section{Agradecimientos}

Quiero agradecer a las autoridades del Museo Histórico "Fuerte Independencia", en especial a la Lic. Bárbara Sosa. Por último, al Dr. José Antonio Vera, cuyos comentarios y sugerencias fueron centrales para la elaboración de este trabajo.

\section{Bibliografía}

Bertoni, L. (2001). "Patriotas, cosmopolitas y nacionalistas. La construcción de la nacionalidad argentina a fines del siglo XIX". Buenos Aires: Fondo de Cultura Económica.

Blasco, M. E. (2007). Los Museos Históricos en la Argentina entre 1889 y 1943. XI Jornadas Interescuelas/ Departamentos de Historia Lugar: Universidad Nacional de Tucumán.

Cattaruzza, A. (2001). Descifrando pasados: debates y representaciones de la historia nacional. En A. CATTARUZZA, (Dir.), Nueva Historia Argentina.

Fernandez Bravo, A (2016). "El museo vacio: acumulación primitiva, patrimonio cultural e identidades colectiva. Argentina y Brasil: 18801945". Ciudad autónoma de Buenos Aires. Editorial EUDEBA.

Lionetti, L. (2007) La misión política de la escuela pública. Formar a los ciudadanos de la república (1870-1916). Buenos Aires: Miño y Dávila Editores.

Morales Moreno, L. G. (2009). "Límites narrativos de los museos de historia", Alteridades, vol. 19, núm. 37, pp. 43-56, Universidad Autónoma Metropolitana Unidad Iztapalapa Distrito Federal, México.

Nora P. (2008). Pierre Nora en Les Lieux de mémoire. Porlogo de Jose Rilla. Montevideo. Ediciones Trilce.

Novaro, G. (2003). "Indios, aborígenes y pueblos originarios. Sobre el cambio de conceptos y la continuidad de los conceptos escolares". Revista educación, lenguaje y sociedad. Vol n¹: 199-219.

Pereyra, E. (2006). Museología, historia, patrimonio y sociedad. Vieregg $H$, Risnicoff de Gorgas M, Schiller R. (eds.), Museología e Historia: un campo de conocimiento, tema 2, XXIX Encuentro Anual del ICOFOM, y XV Encuentro Regional del ICOFOM LAM, Córdoba.

Pérez Calarco, M. I. (2012). Lugones, la hora del cuchillo (entre los dientes). Revista Hispamérica. Año 41, No. 123 (Diciembre 2012), pp. 15-22.

Prieto, A. (1998). "El discurso criollista en la formación de la Argentina moderna", Sudamericana. Buenos Aires.

Pupio, M. A. (2005). "Coleccionistas de objetos históricos, arqueológicos y de ciencias naturales en museos municipales de la provincia de Buenos Aires en la década de 1950", História, Ciencias, Saúde-Manguinhos, V. 12 , PP. 205-229.

Reca, M. M. (2011). Estudio de público de museos: el aporte teórico-metodológico de la semiótica. Revista do 
Museu de Arqueología e Etnología, 21: 357-369.

Sorense Goodich, D. (1997) La conferencia pública en la construcción de los mitos nacionales en la argentina del centenario. In: América: Cahiers du CRICCAL, $n^{\circ} 18$ tome 2. Les Formes brèves de l'expression culturelle en Amérique Latine de 1850 à nos jours : Poésie, Théâtre, Chanson, Chronique, Essai. pp. 559-565.

Uribarren, M. S. (2009). “La Comisión Nacional de Museos y de Monumentos y Lugares históricos de la Argentina entre 1938 y 1946: El patrimonio cultural y la construcción de una idea de Nación", Cuadernos de Historia, Serie Ec. y Soc., Nº 11, CIFFyH-UNC, Córdoba, pp. 213-244.

Vera, J., Soria J. L y G. Seal. (2014). Representaciones del mundo indígena pampeano en ámbitos educativos. En: Mazzanti y Quintana (Eds.) Historias Milenarias Pampeanas. Arqueología de las sierras de Tandilia. Larbo, UNMDP.

Veron, E. (1993). "La semiosis social. Fragmentos de una teoría de la discursividad". Barcelona: Editoral Gedisa. 